\title{
STRIP MODEL FOR STEEL PLATE SHEAR WALLS WITH BEAM- CONNECTED WEB PLATES
}

\author{
Yigit Ozcelik $^{1}$ and Patricia Clayton ${ }^{2}$
}

\author{
${ }^{1}$ Ozyegin University \\ Nisantepe M. Orman S., Cekmekoy, Istanbul, Turkey 34794 \\ e-mail: yigit.ozcelik@ ozyegin.edu.tr \\ ${ }^{2}$ University of Texas at Austin \\ 301 E. Dean Keeton St. Stop C1700, Austin, Texas, USA 78712 \\ clayton@utexas.edu
}

\begin{abstract}
Steel plate shear walls (SPSWs) are a lateral force-resisting system in which thin infill plates (web plates) are connected to the boundary frame (i.e., beams and columns) along four edges. Despite shear buckling of thin plates upon lateral loading, web plates still provide lateral strength and stiffness in the post-buckling range owing to a mechanism called tension field action. The boundary frame (particularly columns) needs to satisfy stringent strength and stiffness requirements to anchor the inclined forces in web plates resulting from tension field action. An alternative system to conventional SPSWs, steel plate shear walls with beamconnected web plates (B-SPSWs), is proposed in the literature where web plates are connected to beams only. Therefore, high flexural and axial load demands in columns induced by tension field forces are eliminated. However, due to the difference in boundary conditions of web plates, the load path of steel plate shear walls with beam-connected web plates significantly differs from that of conventional SPSWs. In this study, a simplified strip model of beamconnected web plate is proposed to simulate the cyclic behavior of beam-connected web plates. As it is typical and conservative to ignore the compressive strength of strips, strip models underestimate the strain energy dissipated under cyclic loading. An equation for the compressive strength of strips is proposed to accurately capture the energy dissipation capacity of beam-connected web plates. A three-way comparison between the proposed strip model, a strip model from the literature, and a validated continuum model is provided. The results reveal that the proposed strip model is capable of successfully estimating the boundary frame demands, lateral load capacity, and energy dissipation of beam-connected web plates.
\end{abstract}

Keywords: Steel Plate Shear Walls, Beam-connected Web Plates, Strip Model, Partial Tension Field, Compressive Strength. 


\section{INTRODUCTION}

Steel plate shear walls (SPSWs) are a reliable lateral force-resisting system with high ductility, high lateral stiffness, and stable hysteretic behavior [1-7]. SPSWs comprise thin infill plates (web plates) connected to beams and columns on all four edges. Under lateral loads, web plates experience shear buckling; however, they are still capable of resisting lateral loads and providing lateral stiffness in the post-buckling range due to diagonal tension stresses developing in web plates called tension field action (TFA) [8]. As the current design practices rely on TFA for the design of SPSWs, diagonal tension stresses in the web plates must be anchored to very stiff beams and columns to utilize TFA efficiently. This diagonal tension might cause significant force demands in beams and columns and require stringent stiffness requirements. It is worthwhile noting that the vertical component of TFA in the web plates of the adjacent stories acting on the intermediate-story beams are in the opposite direction. Consequently, except for the base and roof beams, the flexural demands in the beams of SPSWs might be minimal. However, as diagonal tension stresses in the web plates are exerted on the columns of SPSWs on one side only, the significant internal force demands develop in the columns, which is a design challenge. To mitigate high flexural and axial demands in the columns due to TFA and to facilitate field installation of web plates, an alternative SPSW configuration called SPSWs with beam-connected web plates (B-SPSW) is proposed, in which the web plates are connected to the beams of SPSWs only and the vertical edges of the web plates are free. Within the scope of this paper, the focus is on the modeling of beam-connected web plates. Details of B-SPSWs system design and seismic performance can be found in Ozcelik and Clayton [9-12].

The web plate behavior is typically simulated using two modeling techniques, namely, the continuum model and the strip model. In the former technique, the web plate is modeled using shell-based finite elements with specified initial out-of-straightness to explicitly simulate the shear buckling behavior and to capture the development of TFA under lateral loads. In the later approach, the strip model, the web plate is modeled using a series of inclined tension-only truss elements connected to beams and columns to represent the diagonal tension field of the web plate. The strip model has been utilized successfully by many researchers $[2,8,13-17]$ to simulate the cyclic response of fully-connected web plates (i.e., web plates connected to beams and columns). However, there has been little work done on the development of a strip model for the simulation of cyclic behavior of beam-connected web plates in B-SPSWs.

In the strip model, it is essential to determine the extent and inclination angle of TFA and the hysteretic behavior of individual strips to simulate the cyclic behavior of web plates and to obtain member demands accurately. For fully-connected web plates, design codes $[18,19]$ provide an equation for the inclination angle of tension field. In addition, recent research $[20,21]$ proposed an inclination angle of 45 degrees for fully-connected web plates provided that beams and columns have sufficient stiffness to anchor the web plate to develop full TFA, i.e., diagonal tension stresses develop in the whole plate. As the beam-connected web plates are not restrained by columns along their vertical edges, the extent and inclination angle of the tension field differ from these of fully-connected web plates due to the formation of partial TFA (Figure 1) instead of full TFA. In addition, recent research [20,21] revealed that the tension-only strip behavior is not in alignment with experimental findings and the fullyconnected web plates have non-negligible compressive resistance upon loading and unloading. As the compressive strength of the strips depends on the web plate connectivity and thickness, it should be investigated for beam-connected web plates. 


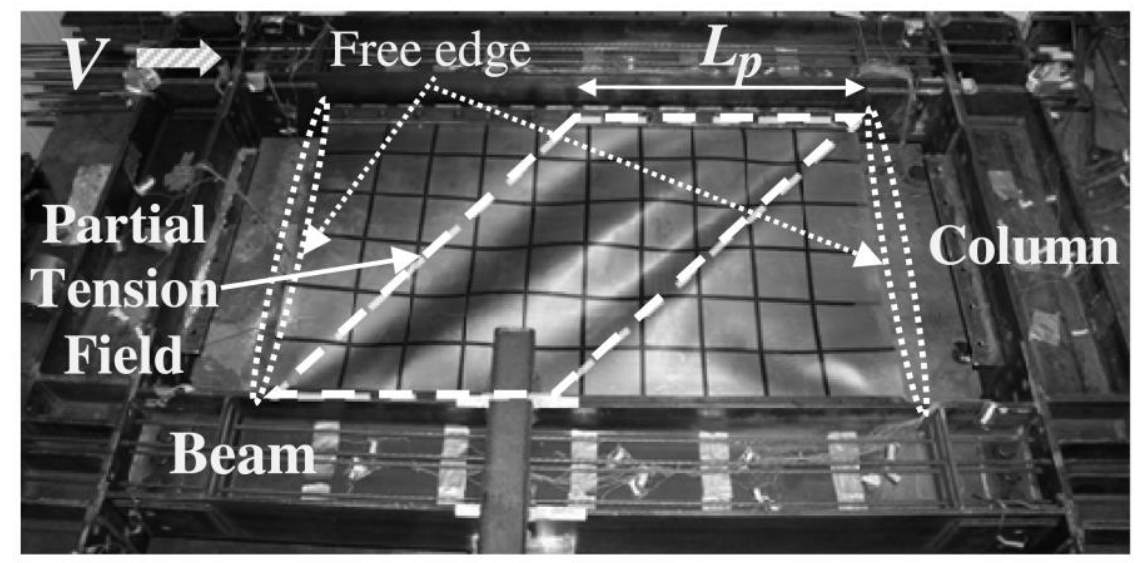

Figure 1: A test photo of partial tension field (adapted from Clayton et al. [16])

In this study, to simulate the beam-connected web plate behavior, a strip model is proposed, providing equations for the inclination angle of tension field and the compressive strength of strips. The details of the strip model are explained and a three-way comparison between the proposed strip, a strip model in the literature, and a continuum model is presented.

\section{STRIP MODEL FOR BEAM-CONNECTED WEB PLATES}

Thorburn et al. [8] was proposed a strip model for fully-connected web plates with infinitely flexible columns. In this model, Thorburn et al. [8] assumed that partial TFA would form in the web plate between the beams over the partial TFA length $\left(L_{p}\right)$ as the columns could not anchor the diagonal tension stresses in the web plate. Assuming the PTF orients itself to resist the maximum shear force, Thorburn et al. [8] proposed an equation for the inclination angle of partial TFA (Equation 1), where $\gamma$ is a non-dimensional inclination angle parameter given as 0.5 .

$$
\theta=\gamma \tan ^{-1}(L / H)
$$

Thorburn et al. [8] defined $L_{p}$ based on web plate geometry and an assumed $\theta$ (Equation 2), where $L$ and $H$ are the web plate length and height, respectively:

$$
L_{p}=L-H \tan \theta=L\left(1-\frac{\tan \theta}{L / H}\right)
$$

The strip model proposed by Thorburn et al. [8] can be extended to beam-connected web plates as partial TFA is observed in beam-connected web plates under lateral loads. Characterizing thin beam-connected web plate behavior adopting a mechanics-based analytical model and a validated detailed finite element of a beam-connected web plate, Equation 3 is proposed for $\gamma$. Details of Equation 3 can be found in Ozcelik and Clayton [22,23].

$$
\gamma=0.55-0.03(L / H) \geq 0.51
$$

As discussed herein, compressive strength of SPSW web plates is typically neglected since it is assumed that web plates have limited shear buckling strength. A parametric study was conducted by Ozcelik and Clayton [22] to quantify the compressive strength of strips representing beam-connected web plates. A parameter, $\beta$, is defined as the ratio of compressive strength of the strip to the yield strength, $F_{y}$, of the web plate material, given by Equation 4, where $t_{w}$ is the web plate thickness: 


$$
\beta=-0.04+0.02(L / H)+\frac{2.75}{\sqrt{H / t_{w}}} \geq 0
$$

Adding an elasto-plastic material with a compressive strength determined by Equation 4 (Figure 2(b)) to the tension-only pinched material for which tensile stresses do not develop until reaching the maximum plastic strain from previous cycles (Figure 2(a)) in parallel, a parallel material (Figure 2(c)) can be used to simulate the strip behavior under cyclic loading. The normalized stress and strain diagrams of the materials are given in Figure 2, where $\sigma$ is the stress in strips, $\varepsilon$ is the normal strain of strips, and $\varepsilon_{y}$ is the yield strain of the web plate material.
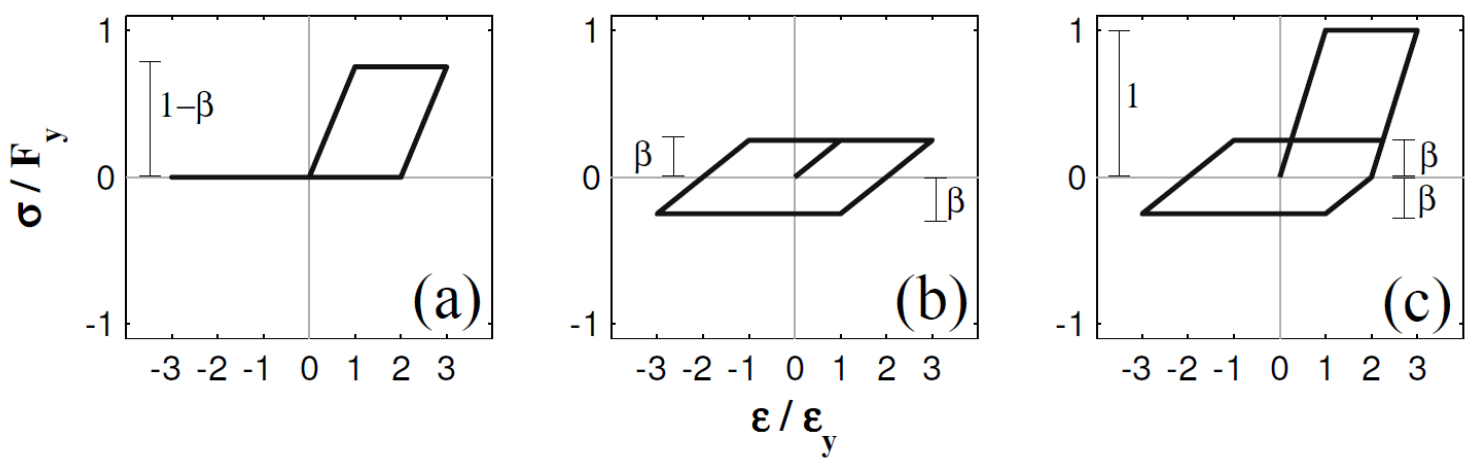

Figure 2: Material models for strips: (a) pinched tension-only material, (b) elasto-plastic tension-compression material, and (c) resulting strip response when (a) and (b) are used in parallel. (adapted from Ozcelik and Clayton [22])

The area of a strip, $A_{s}$, can be calculated using Equation 5, where $n_{s}$ is the number of strips in each direction:

$$
A_{s}=t_{w} L_{p} \cos \theta / n_{s}=t_{w} L\left(1-\frac{\tan \theta}{L / H}\right) \cos \theta / n_{s}
$$

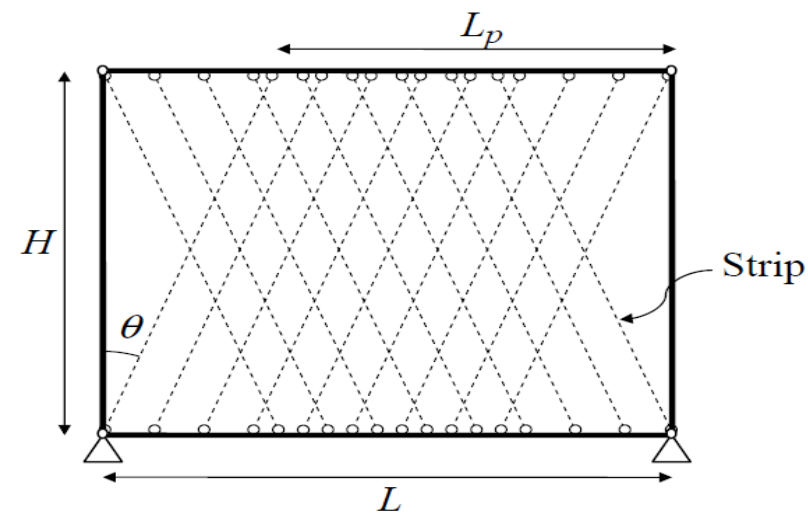

Figure 3: Strip model. (adapted from Ozcelik and Clayton [22])

The step-by-step modeling of the proposed strip model is described as follows:

- Determine $\gamma$ and $\theta$ using Equations 3 and 1, respectively.

- Calculate $L_{p}$ using Equation 2.

- Select the number of strips (at least 10 strips to improve accuracy) and calculate $A_{s}$ from Equation 5. 
- Estimate $\beta$ from Equation 4.

- Define the strip material as a combination of materials in parallel given in Figure 2(a) and Figure 2(b).

- Create a series of evenly-spaced inclined strips using truss elements as shown in Figure 3.

\section{COMPARISON OF B-SPSW MODELS}

A three-way comparison between the proposed strip model, a strip model in the literature, and the continuum model is provided. B-SPSWs with various aspect ratios $(L / H)$ between 0.8 and 2.5 keeping $H$ constant $(4 \mathrm{~m})$ and height-to-thickness ratios between 160 and 3200 are analyzed under a cyclic drift history in ABAQUS [24] adopting the continuum model approach where the web plates are represented by shell elements (S4R) with an initial imperfection and beams and columns are modeled using very stiff line elements (B31). These models will be referred to as finite element models (FEM). The same B-SPSWs are modeled in OpenSEES adopting the strip model approach proposed herein. As the proposed strip model accounts for the compressive strength of the strips, it will be referred to as tensioncompression strip model (TC). In addition to the proposed strip model, B-SPSWs are modeled in OpenSEES adopting the strip model proposed by Thorburn et al. [8], in which $\gamma$ is 0.5 and $\beta$ is 0 (i.e., tension-only strips). The strip model proposed by Thorburn et al. [8] will be referred to as tension-only strip model (TO). Similar to FEM, the beams and columns of the TC and TO models are modeled using very stiff line elements. Further details on the modeling of FEM, TC, and TO can be found in Ozcelik and Clayton [22].

The analysis results from the strip models (TC and TO) and FEMs are compared in terms of base shear capacity of beam-connected web plates, beam and column demands, and energy dissipation capacity of B-SPSWs. Figure 4 shows the comparison of the base shears, $V$, normalized with respect to the web plate lateral load capacities, $V_{y}$, of three models with an aspect ratio of 1.5 for various $H / t_{w}$ ratios. $V_{y}$ can be calculated from Equation 6:

$$
V_{y}=0.5 F_{y} t_{w} L_{p} \sin 2 \theta
$$

As depicted in Figures 6(a) and 6(b), for thinner web plates (higher $H / t_{w}$ ), both TO and TC match the FEM results closely as the strips representing thinner web plates have limited compressive strength. The normalized base shear capacities and the normalized unloading base shears are closed to 1 and 0 , respectively, for all models, as expected. For thicker plates (Figures 6(d) and 6(e)), TC still shows a very similar response to FEM while TO does not match FEM. As thicker plates are used, TC is able to predict peak capacities accurately; however, it does tend to underestimate the web plate strength during unloading and loading. The loading and unloading strengths might have a substantial impact on the energy dissipation capacity; however, they do not affect the peak beam and column demands as will be discussed.

By integrating the area under the base shear vs. displacement response for each model, energy dissipation (E) is determined. For a $L / H$ of 1.5 and $H / t_{w}$ of 213 , Figure 5 shows $E$ for each model normalized with respect to the total energy dissipated in FEM $\left(E_{\max }\right)$. As mentioned, the TC model underestimates the unloading and loading strengths; consequently, the TC model underpredicts $E$ by approximately $25 \%$ for thicker plates with respect to the FEM results. On the other hand, the TO model underestimates $E$ by approximately $75 \%$ for the same plate thickness with respect to the FEM results. 

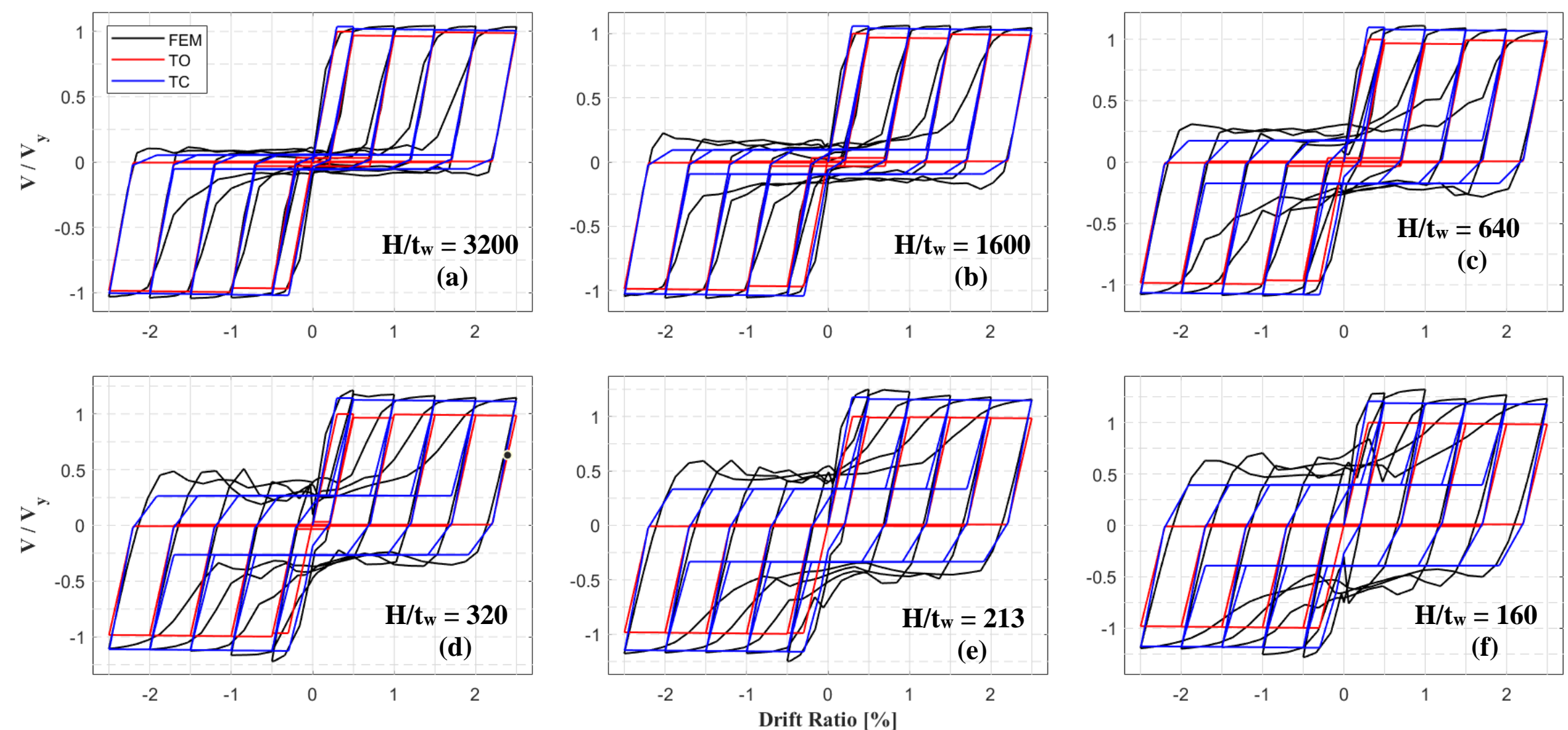

Figure 4: Comparison of normalized base shear vs. drift ratio for an aspect ratio of 1.5 


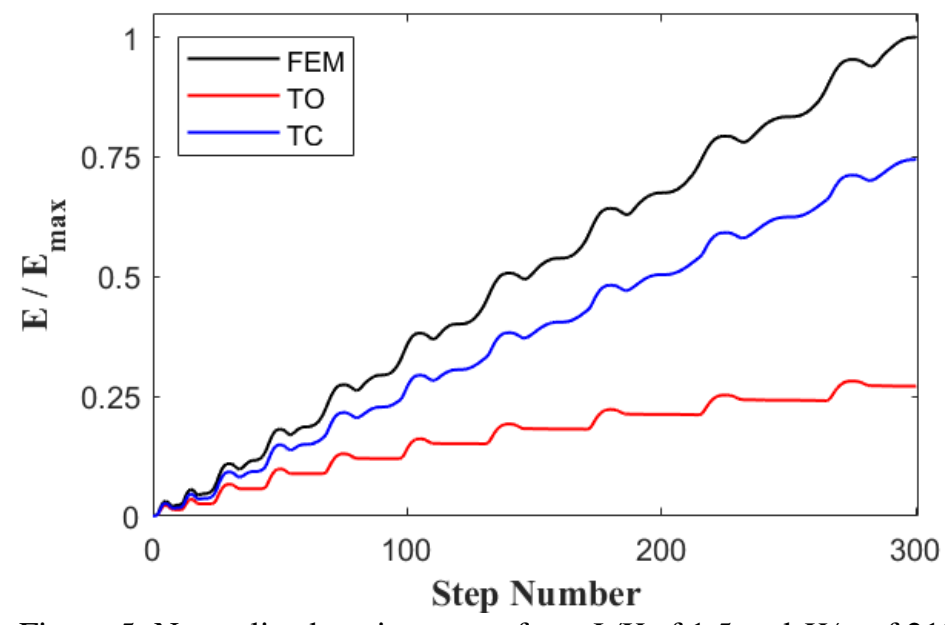

Figure 5: Normalized strain energy for a $L / H$ of 1.5 and $H / t_{w}$ of 213

For various $L / H$ and $H / t_{w}$, the normalized strain energy $\left(E / E_{\max }\right)$ values are tabulated in Tables 1 and 2 for TC and TO models, respectively. For the thinnest and the thickest plates considered in this study $\left(\left(H / t_{w}\right.\right.$ of 1600 and 160 , respectively), TO can dissipate approximate $50 \%$ and $25 \%$ of $E_{\max }$ (on average), respectively. However, TC can dissipate as high as $84 \%$ of $E_{\max }$ on average. Despite underprediction of energy dissipation, TC shows a great improvement in simulating beam-connected web plate behavior compared to the existing TO in terms of energy dissipation capacity.

\begin{tabular}{|c|c|c|c|c|c|c|c|c|c|c|c|c|}
\hline \multirow[b]{3}{*}{$L / H$} & \multicolumn{3}{|c|}{$M_{\max }$} & \multicolumn{3}{|c|}{$P_{\max }$} & \multicolumn{3}{|c|}{$V$} & \multicolumn{3}{|c|}{$E$} \\
\hline & \multicolumn{3}{|c|}{$H / t_{w}$} & \multicolumn{3}{|c|}{$H / t_{w}$} & \multicolumn{3}{|c|}{$H / t_{w}$} & \multicolumn{3}{|c|}{$H / t_{w}$} \\
\hline & 160 & 320 & 1600 & 160 & 320 & 1600 & 160 & 320 & 1600 & 160 & 320 & 1600 \\
\hline 1.1 & 1.16 & 1.06 & 1.06 & 0.96 & 0.98 & 1.04 & 0.89 & 0.92 & 0.96 & 0.75 & 0.76 & 0.81 \\
\hline 1.4 & 1.03 & 1.16 & 1.04 & 0.94 & 1.05 & 1.03 & 0.92 & 0.98 & 0.99 & 0.78 & 0.79 & 0.84 \\
\hline 1.7 & 1.17 & 1.14 & 1.04 & 1.08 & 1.03 & 1.04 & 0.96 & 0.98 & 0.99 & 0.80 & 0.80 & 0.81 \\
\hline 2.0 & 1.12 & 1.12 & 1.03 & 1.06 & 1.07 & 1.03 & 0.99 & 1.01 & 1.00 & 0.83 & 0.83 & 0.84 \\
\hline 2.3 & 1.07 & 1.16 & 1.05 & 1.05 & 1.06 & 1.03 & 1.01 & 1.02 & 0.99 & 0.95 & 0.92 & 0.90 \\
\hline Average & 1.09 & 1.09 & 1.04 & 1.01 & 1.03 & 1.04 & 0.94 & 0.98 & 0.98 & 0.82 & 0.84 & 0.85 \\
\hline Std. Dev. & 0.07 & 0.06 & 0.02 & 0.06 & 0.04 & 0.01 & 0.07 & 0.04 & 0.02 & 0.08 & 0.06 & 0.04 \\
\hline
\end{tabular}

Table 1: Beam Moment, Column Axial Load, Base Shear, and Energy Ratios (TC Model to ABAQUS Ratios)

\begin{tabular}{|c|c|c|c|c|c|c|c|c|c|c|c|c|}
\hline \multirow[b]{3}{*}{$L / H$} & \multicolumn{3}{|c|}{$M_{\max }$} & \multicolumn{3}{|c|}{$P_{\max }$} & \multicolumn{3}{|c|}{$V$} & \multicolumn{3}{|c|}{$E$} \\
\hline & & $H / t_{w}$ & & & $H / t_{w}$ & & & $H / t_{w}$ & & & $H / t_{w}$ & \\
\hline & 160 & 320 & 1600 & 160 & 320 & 1600 & 160 & 320 & 1600 & 160 & 320 & 1600 \\
\hline 1.1 & 1.45 & 1.24 & 1.15 & 1.09 & 1.08 & 1.10 & 0.64 & 0.80 & 0.94 & 0.24 & 0.30 & 0.54 \\
\hline 1.4 & 1.31 & 1.37 & 1.13 & 1.07 & 1.15 & 1.09 & 0.76 & 0.82 & 0.94 & 0.23 & 0.30 & 0.51 \\
\hline 1.7 & 1.48 & 1.37 & 1.14 & 1.23 & 1.15 & 1.10 & 0.77 & 0.87 & 0.95 & 0.27 & 0.33 & 0.51 \\
\hline 2.0 & 1.44 & 1.35 & 1.14 & 1.21 & 1.19 & 1.09 & 0.79 & 0.88 & 0.95 & 0.27 & 0.33 & 0.50 \\
\hline 2.3 & 1.36 & 1.36 & 1.12 & 1.21 & 1.17 & 1.09 & 0.82 & 0.88 & 0.96 & 0.28 & 0.35 & 0.53 \\
\hline Averag & 1.39 & 1.31 & 1.14 & 1.15 & 1.13 & 1.10 & 0.75 & 0.84 & 0.94 & 0.25 & 0.33 & 0.52 \\
\hline Std. Dev. & 0.10 & 0.09 & 0.02 & 0.08 & 0.06 & 0.01 & 0.08 & 0.04 & 0.01 & 0.02 & 0.03 & 0.03 \\
\hline
\end{tabular}

Table 2: Beam Moment, Column Axial Load, Base Shear, and Energy Ratios (TO Model to ABAQUS Ratios)

Tables 1 and 2 tabulate the ratios of maximum moment in beams $\left(M_{\max }\right)$, maximum axial compressive load in columns $\left(P_{\max }\right)$, and $V$ of strip models to those of FEM. TO overestimates 
$M_{\max }$ and $P_{\max }$ conservatively for all $H / t_{w}$ values; however, TO becomes overly conservative as plate thickness increases. TO successfully predicts $V$ for thinner plates while $V$ of TO can be as low as $60 \%$ of $V$ of FEM for thicker plates. These differences stem from the negligible compressive strength assumption for TO. TC predicts the $M_{\max } P_{\max }$, and $V$ accurately regardless of the plate thickness as TC accounts for the compressive strength of strips. For the cases in which TC deviates from FEM, the member demands are typically conservatively overestimated and base shear tends to be conservatively underestimated for TC. In brief, TC can be used to model beam-connected web plates for a wide range of $L / H$ and $H / t_{w}$ values.

\section{CONCLUSIONS}

In this study, a simplified model called strip model is proposed to simulate the behavior of beam-connected web plates under cyclic loading. An equation is presented for the inclination of tension field action observed in beam-connected web plates and another equation is provided that estimates the compressive strength of strips. A three-way comparison between the proposed strip model, the strip model proposed by Thorburn et al. [8], and the shell-based finite element model is presented. The results of the comparative study appear to indicate that the proposed strip model matches the finite element results and shows a significant improvement in simulating beam-connected web plate behavior compared to the strip model proposed by Thorburn et al. [8].

\section{REFERENCES}

[1] Driver RG, Kulak GL, Kennedy DJL, Elwi AE. Seismic behavior of steel plate shear walls. Structural Engineering Report No. 298. University of Alberta. Edmonton, AB: 1997.

[2] Driver R, Kulak G, Elwi AE, Kennedy D. FE and simplified models of steel plate shear wall. J Struct Eng 1998;124:121-30. doi:10.1061/(ASCE)0733-9445(1998)124:2(121).

[3] Elgaaly M. Thin steel plate shear walls behavior and analysis. Thin-Walled Struct 1998;32:151-80. doi:10.1016/S0263-8231(98)00031-7.

[4] Kulak G, Kennedy D, Driver R. Discussion of "Experimental Study of Thin Steel Plate Shear Walls under Cyclic Load" by Vincent Caccese, Mohamed Elgaaly, and Ruobo Chen (February, 1993, Vol. 119, No. 2). J Struct Eng 1994;120:3072-3. doi:10.1061/(ASCE)0733-9445(1994)120:10(3072).

[5] Rezai M. Seismic behavior of steel plate shear walls by shaking table testing. University of British Columbia, 1999.

[6] Roberts TM, Sabouri-Ghomi S. Hysteretic characteristics of unstiffened perforated steel plate shear panels. Thin-Walled Struct 1992;14:139-51. doi:10.1016/02638231(92)90047-Z.

[7] Sabelli R, Bruneau M. Steel design guide: Steel plate shear walls. AISC; 2012.

[8] Thorburn L, Kulak G, Montgomery C. Analysis of steel plate shear walls. Structural Engineering Report No. 107. University of Alberta. Edmonton, AB: 1983.

[9] Ozcelik Y, Clayton P. Seismic design and performance of SPSWs with beamconnected web plates. J Constr Steel Res 2018;142:55-67.

[10] Ozcelik Y, Clayton PM. Behavior of columns of steel plate shear walls with beamconnected web plates. Eng Struct 2018;172:820-32. 
doi:10.1016/j.engstruct.2018.06.087.

[11] Ozcelik Y, Clayton PM. Effect of flexural demands in the leaner columns on the column buckling strength. Proc. 11th Natl. Conf. Earthq. Eng., Los Angeles, CA: 2018.

[12] Ozcelik Y, Clayton PM. Seismis performance of SPSWs with beam-connected web plates designed for low-seismic regions. Proc. 16th Eur. Conf. Earthq. Eng., Thessaloniki, Greece: 2018.

[13] Clayton PM, Tsai C-Y, Berman JW, Lowes LN. Comparison of web plate numerical models for self-centering steel plate shear walls. Earthq Eng Struct Dyn 2015;44:2093110. doi:10.1002/eqe.2578.

[14] Guo L, Li R, Zhang S, Yan G. Hysteretic analysis of steel plate shear walls (SPSWs) and a modified strip model for SPSWs. Adv Struct Eng 2012;15:1751-64. doi:10.1260/1369-4332.15.10.1751.

[15] Lubell AS, Prion HGL, Ventura CE, Rezai M. Unstiffened steel plate shear wall performance under cyclic loading. J Struct Eng 2000;126:453-60. doi:10.1061/(ASCE)0733-9445(2000)126:4(453).

[16] Clayton PM, Berman JW, Lowes LN. Seismic performance of self-centering steel plate shear walls with beam-only-connected web plates. J Constr Steel Res 2015;106:198208. doi:10.1016/j.jcsr.2014.12.017.

[17] Shishkin J, Driver R, Grondin G. Analysis of steel plate shear walls using the modified strip model. J Struct Eng 2009;135:1357-66. doi:10.1061/(ASCE)ST.1943541X.0000066.

[18] AISC. ANSI/AISC 341-16 Seismic provisions for structural steel buildings. Chicago, IL: American Institute for Steel Construction (AISC); 2016.

[19] CAN/CSA. CAN/CSA-S16-09 Design of steel structures. Mississauga, ON: Canadian Standards Association; 2009.

[20] Webster DJ, Berman JW, Lowes LN. The elastic and inelastic post-buckling behavior of steel plate shear wall web plates and their interaction with vertical boundary elements. Proc. Annu. Stab. Conf. Struct. Stab. Res. Counc., Grapine, TX: 2012.

[21] Webster DJ. The inelastic seismic response of steel plate shear wall web plates and their interaction with the vertical boundary members (Ph.D. Dissertation). University of Washington, 2013.

[22] Ozcelik Y, Clayton P. Strip model for steel plate shear walls with beam-connected web plates. Eng Struct 2017;136:369-79. doi:10.1016/j.engstruct.2017.01.051.

[23] Ozcelik Y, Clayton P. Tension field inclination angle in steel plate shear walls with beam- connected web plates. Second Int. Conf. Nat. Hazards Infrastruct., Chania, Greece: 2019.

[24] ABAQUS. ABAQUS version 6.10 documentation. Simulia; 2010. 